\title{
Aspectos atuais do Direito Civil *.
}

\author{
Washington de B. Monteiro \\ Catedrático de Direito Civil na Faculdade de \\ Direito da Universidade de São Paulo.
}

1. Dispondo sôbre o ano letivo, prescreve a lei orgânica desta Faculdade (Lei n. 3.023, de 15-7-37, art. 87, $\S 2 .^{\circ}$ ), que haverá uma aula solene de abertura e outra de encerramento, por um catedrático convidado pelo $\mathrm{Di}$ retor, de preferência entre os mais antigos para a segunda e os mais recentes para a primeira.

Distinguido por honroso convite do exmo. sr. diretor, professor Luíz ANTônio da Gama e Silva, aqui me encontro para proferir a presente aula inaugural, que assinala, nesta Faculdade, o início do ano escolar de 1961. Porque dirigida, aos estudantes de tôdas as séries, deve a mesma versar tema jurídico de interêsse geral; e porque se pronuncie perante a douta congregação, em cerimônia solene, há de ser erudita e formal.

Começo-a, por dirigir-me, em primeiro lugar, e de um modo todo especial, à mocidade estudiosa desta casa, que é, na frase sincera e sempre oportuna de Pimenta Bueno, a luz que se acende, que cresce e que em breve irá resplandecer.

A essa juventude, que vem em busca de ensinamentos, numa fase de generosa intensidade mental, deve o professor sua ciência, tôda a sua ciência. A ela deve o labor de seus estudos, o tributo de suas pesquisas e o resultado de suas meditações. Seu magistério há de ser como um

* Aula-inaugural do Curso de Bacharelado proferida em 10 de abril de 1961 no salão nobre da Faculdade de Direito da Universidade de São Paulo. 
livro aberto ante os olhos de seus ouvintes. Nesse esfôrço diuturno, traçando o roteiro da lição, dispondo-lhe a matéria, selecionando os argumentos, prevendo as objeções, removendo as dificuldades e recrutando os autores, subindo das fontes para as vastas perspectivas doutrinárias e institucionais, o professor dá a luz de seus olhos, o lume de sua inteligência e o palpitar de seu coração.

Como Mr. Chips, do famoso romance de Hitton, êle vê o aluno e pode guardá-lo na memória ou no coração e sua maior glória no expressivo dizer de Gustavo Corção, é sua continuidade, através de seus discípulos. Quão grande é sua alegria, quão generosa a sua recompensa, quando, além de iniciá-los nos princípios gerais da ciência, fornecendo-lhes os meios de ampliar seus conhecimentos, consegue ainda despertar-lhes idéias e sentimentos e incrementar seu amor ao estudo! Essa comunicação intelectual, que aproxima professôres e alunos, constitui para àquêles o maior galardão.

Em segundo lugar, desejo dirigir-me ainda à ilustre congregação desta Faculdade, que tanto mais admiro quanto mais com ela convivo, sempre sábia, desinteressada e prudente, muitas vêzes incompreendida, e que, como suas gloriosas antecessoras no passado, desta casa faz, no presente, uma escola de civismo e de liberdade, de tradição e de cultura, de exemplo e de abnegação.

Para cada um dos eminentes mestres, que me desvanecem com sua atenção, ensinar é a própria vida, a sua glória, a sua razão de ser, tanto na cátedra, como no livro. Sua pregação jamais será esquecida, porque germinada nas profundas camadas de sua alma e dada de todo coração.

Endereçando aos primeiros, os estudantes de minha terra, os mais sinceros votos de proveitoso estudo, neste limiar do ano letivo, e aos segundos, os caros mestres que me ouvem, as homenagens do meu respeito, desejo formular um anelo, o de que para sempre permaneçam unidos os filhos espirituais desta casa, em tôrno dos ideais que aqui haurimos e que aprendemos aqui a cultuar. 
Se a grandeza de uma profissão é talvez, antes de tudo, a de unir os homens, como afirma SaInt Exupery, tal união, nesta escola, que é o nosso templo, será a nossa fôrça, a espelhar, no vigor de nossos sentimentos, na densidade de nossas convicções, tôda a fé, tôda a crença, na dignidade e na respeitabilidade da profissão que abraçamos.

2. Inicia Roberto DE Ruggiero suas admiráveis Instituições de Direito Civil, lembrando que o direito surge espontâneamente em todos os atos, pois, tôda a nossa existência, do berço ao túmulo, se desenrola através de infinita série de manifestações jurídicas. Em quase todos os momentos da vida de cada um de nós, até mesmo naqueles que à primeira vista parecem insignificantes ou despidos de qualquer relêvo, no lar, na sociedade ou no exercício da profissão, desponta o direito, continuamente vivido pelos homens, ainda que êstes não se tenham intencionalmente proposto à realização de atos jurídicos.

O eminente civilista italiano exemplifica: o viajante que na praia recolhe a concha trazida pelas ondas; o fumante que, despreocupado, deita fora a ponta de seu cigarro; o lavrador que, semeando em suas terras, deixa cair algumas sementes no campo do vizinho.

Sem que disso tenham noção, todos três estão a praticar atos jurídicos, disciplinados pela lei civil: o primeiro, a ocupação, o mais antigo dos modos de adquirir a propriedade e o mais importante, talvez, nas sociedades primitivas, e através do qual incorpora ao seu domínio uma res nullius; o segundo, verdadeiro e próprio abandono, por meio do qual abre mão do que lhe pertence; e o terceiro, finalmente, a acessão, pois, embora não deliberadamente, torna o vizinho proprietário das sementes que, de modo acidental,tombaram em seu terreno.

Transportêmo-nos, porém, para a nossa própria época, para o nosso ambiente, em que vivemos e em que lutamos. A tese de início afirmada, o da presença do direito em todos os atos da vida, volta a encontrar a mais ampla 
aplicação. Assim, desde que hoje deixamos nossas casas, em demanda desta Faculdade, viemos realizando, seguidamente, ininterruptamente, inúmeros atos jurídicos.

Com efeito, quando tomamos um ônibus ou um carro de praça, quando adquirimos uma revista na banca do jornaleiro, ou quando emprestamos certo livro a um colega, em todos êsses atos triviais, e em muitos outros que a nossa imaginação fàcilmente poderia sugerir, o direito aparece de modo intenso, dominador e eterno, a reger as mútuas relações entre os homens.

E a vida individual, como a social, a vida familiar como a profissional, nas suas mais humildes como nas suas mais graves manifestações, assim transcorre, ora serena, ora de maneira turbulenta, no meio de sucessivas e incessantes afirmações jurídicas. $O$ direito domina inteiramente a vida dos homens, êle constitui um rítmo da própria vida, no dizer de D'annunzıo, o soberano do mundo, na frase de Mirabeau.

Seu escopo é precisamente o de regular a convivência humana, ministrando-lhe regras de comportamento. Mas, que é o direito? Eis aí o cruciante problema de filosofia jurídica, que até agora ainda não foi solvido, sôbre o qual ainda não desceu a cortina das soluções tranqüilizadoras e definitivas.

Várias são as doutrinas que procuram elucidá-lo, porque em jôgo estão as questões mais essenciais sôbre o próprio sentido da vida. A noção do direito reveste-se de múltiplos aspectos, conforme a escola a que se pertença, conforme o prisma pelo qual seja êle encarado. Será êle pura criação do espírito e que reflete um ideal, como querem alguns? Ou resulta êle de circunstâncias de fato, é um produto social, como pretendem outros?

Acreditamos, porém, com Grongio Del Vecchio, que é no santuário da consciência, na constituição intrínseca do indivíduo, que se deve buscar a lei suprema do ser e do conhecìmento. É lá ainda que se encontra a fonte do direito e do dever e por isso se diz que o mesmo deve constituir a mais alta expressão da probidade humana. 
3. Mas a vida, individual e social, familiar e profissional, é complexa. Além de complexa, eminentemente mutável, no tempo e no espaço. A vida não pode ser estática e inerte. A transformação constante é a sua própria condição. Se ela se detivesse um só momento, se ela perdesse êsse dinamismo, que é a sua característica, daria lugar à morte.

Ora, o direito é uma face da vida e por isso é também mutável e contingente como a própria vida. Desdobra-se, por isso, em inúmeros aspectos, de acôrdo com a seqüência desta. Só assim poderá satisfazer as exigências da sociedade moderna, só assim êle se colocará ao nível da atual estrutura social.

Não é de admirar, portanto, que, contemplado no seu conjunto, êle se apresente como um mundo, repleto de recantos inexplorados, em que as surprêsas se sucedem a cada passo. Eis porque seu estudo representa algo de infinito, capaz de consumir a vida inteira. Por mais que estudemos, por mais que nos esforcemos, sempre remanescem as dúvidas, cada vez mais densas e profundas. $E$ ao término da jornada, quando descansamos o nosso cajado de peregrinos, persistem ainda as mesmas interrogações, subsistem as mesmas perguntas sem resposta: ignoramus et ignorabimus.

4. Conquanto nos limitemos ao direito civil apenas, teremos desde logo a firme intuição de tôdas as suas complexidades. Embora seu estudo, nas Faculdades de Direito, seja proporcionado em quatro anos, bem pálida e bem incompleta é a idéia que o professor dêle consegue transmitir aos seus alunos.

Não é de admirar, portanto, a confissão de GaBBA, externada numa cerimônia como a de hoje: "a emprêsa que se intitula curso de direito civil é de tal monta que chega a intimidar espíritos bem mais potentes e bem mais argutos do que o meu".

Por certo, não existe domínio mais tormentoso. Êle cinge a vida individual na infinita variedade de suas ma- 
nifestações. Antecede ao nosso nascimento e sobrevive ao nosso desaparecimento. Segue-nos como um companheiro fiel, em todos os passos de nossa existência. É como o oxigênio que nos renova o sangue, o alimento que nos retempera as fôrças, o ponto de apoio que nos sustenta em nossos desfalecimentos. É como a nossa sombra, a nossa própria natureza, com a qual caminhamos lado a lado, com a qual dialogamos face a face.

Restrinjâmo-nos, todavia, neste ensejo, a um rápido olhar sôbre o aspecto externo dêsse edifício, sem penetrar-lhe o interior e sem perlustrar-lhe, passo a passo, os. seus recantos.

5. Comecemos assim por lançar uma vista de olhos sôbre o direito das obrigações. Afirmou Domat outrora que o direito das obrigações era um direito estático. Era a parte imutável do direito. Suas regras seriam universais e eternas, como as da aritmética e da geometria.

Trata-se, porém, de uma ilusão, como demonstra Planiol. Sem dúvida, essa matéria é menos vulnerável aos contragolpes das revoluções políticas. As concepções romanas nela se mantiveram com maior persistência, revelando maior estabilidade, maior firmeza, que em outras partes do direito civil.

Mas ela não escapou também à ação do tempo, embora mais lentas e mais demoradas as suas transformações. Se històricamente examinarmos o instituto das obrigações, verificaremos, com efeito, que sua sorte se acha intimamente ligada ao problema da liberdade.

Numa primeira fase, correspondente à primitiva antigüidade, o indivíduo, isoladamente considerado, nada representava, sendo inteiramente absorvido pela coletividade. E a fase da completa assimilação do elemento individual pelo elemento social. Não tendo esfera de vida própria e de atividade própria, o indivíduo não tinha igualmente objeto de interêsse próprio, de que pudessem se originar relações obrigatórias de direito privado. 
Numa segunda fase, porém, ocorre a completa emancipação do elemento individual, que se desliga do elemento social. De simples zero à esquerda, êle se converte na figura preeminente do cenário jurídico. $O$ indivíduo passa a ser tudo e o Estado apenas intervém para assegurar-lhe a eficácia da vontade. É o triunfo do individualismo, que liberta o indivíduo da onipotência do Éstado, a exaltação do indivíduo, que se torna o denominador comum de tôdas as instituições jurídicas, a razão de ser do Estado. Laissez faire, laissez passer é a fórmula que, por muito tempo, foi a suprema diretriz da política econômica, que bem traduz êsse estágio da cultura humana e retrata a posição do Estado em face do indivíduo.

Mas, não tardam a aparecer as falhas dêsse sistema de isolamento, oposto ao espírito de associação, e que faz prevalecer os direitos do indivíduo sôbre os da coletividade. $O$ individualismo gera o capitalismo. À sombra dêste surgem as grandes emprêsas, os vastos consórcios, sob as formas de sociedades anônimas, monopólios, trusts e cartéis. São entidades abstratas, impessoais, insensíveis à piedade, que provocam, com o seu acendrado egoismo, a luta de classes, causa de tantas e tão profundas perturbações sociais, porque o proletariado, tratado com desumanidade, procurou também aglutinar-se para defender-se melhor, de modo que num imenso campo de batalha se transformou o mundo contemporâneo, com patrões e empregados a se olharem como inimigos, na frase sugestiva de Zola.

A tal ponto chegou então a incompreensão entre os rivais, que os benefícios concedidos pela classe patronal foram chamados de reclame eleitoral pela classe operária. $\mathrm{E}$ aos seus sacrifícios financeiros se denominou de seguro contra a revolução.

Busca-se assim, numa terceira e última fase, obter o apaziguamento dos espíritos: nas repúblicas populares, pela socialização da propriedade e.dos meios de produção, nos estados totalitários, pela reintegração do elemento individual no elemento social, nas democracias do ocidente, 
pelo respeito ao indivíduo, mas em colaboraçãu com a sociedade.

Procura-se obter assim um mundo melhor, impregnado de maior tolerância, em que possamos obter nosso aperfeiçoamento moral e espiritual, e em que a lei não seja mero instrumento de compressão, ou um odre vasio, que cada um encha a seu gôsto.

Ésse o alto sentido, que se contém em nosso estatuto político, que dispõe, como princípio constitucional: "a ordem econômica deve ser organizada conforme os princípios da justiça social, conciliando a liberdade de iniciativa com a valorização do trabalho humano" (Constituição Federal, art. 145).

Aquela evolução não poderia deixar de influir, como realmente influiu, de modo decisivo, no direito das obrigações, cuja fisionomia sofreu, e continua ainda a sofrer, profundas modificações, em virtude da atuação de novas idéias, mais justas, mais generosas e mais humanas.

Tome-se como exemplo o importante capítulo reservado à locação de serviços. Nessa matéria, além de deficiente, mostrara-se o Código de grande dureza, submetendo o trabalho à férrea lei da oferta e da procura, esquecendo-se do contrato coletivo, omitindo o direito de greve, pondo de lado o trabalhador agrícola e não pronunciando, uma vez siquer, como nota LACERDA DE Almerda, a palavra eqüidade.

Felizmente, não mais perdura essa situação e agora constituem preceitos constitucionais muitas das numerosas conquistas das classes trabalhadoras, concernentes ao salário mínimo, ao repouso semanal remunerado, ao direito à estabilidade, à previdência social e outras. O próprio direito de greve obteve expressa consagração legal.

No tema da responsabilidade civil, caminhamos decididamente da responsabilidade subjetiva para a responsabilidade objetiva. Procuramos substituir a idéia da culpa pela idéia do risco e o direito atual tende a colocar a idéia da reparação no lugar da idéia da responsabilidade. 
Dizia-se outrora, e a frase é de Ripert, que sendo fortuito o caso, não havia mais que deixar a vítima gemer sob o golpe do destino. Hoje, diz-se que entre o fraco e o forte não há que hesitar e o risco deve recair sôbre aquêle que é capaz de suportar.

A concepção clássica da autonomia da vontade e da qual decorre o princípio de que o contrato faz lei entre as partes, já não tem mais caráter absoluto como antigamente. Pacta sunt servanda não mais representa princípio intangivel. Sob o influxo da eqüidade, que personifica a humanidade no direito, bem como da socialização dêste, sobretudo para que o contrato deixe de servir à exploração dos fracos e humildes, acentua-se, cada vez mais, o afrouxamento da regra, e, através do dirigismo contratual, busca-se controlá-lo para assegurar o respeito aos direitos fundamentais da pessoa humana.

Bastam êsses pontos, colhidos dentre muitos outros, para deixar ressaltado que o direito das obrigações não é estacionário, impermeável à transformação e ao progresso. Muito ao revés, sofre êle contínuas alterações, que lhe alteram o aspecto tradicional com que, até há pouco, se apresentava aos olhos da doutrina.

6. Voltêmo-nos agora para o direito das coisas, sem dúvida a parte mais difícil do direito civil. Eis aí o ramo que, por mais longo tempo, se manteve fiel à tradição romana e aos princípios individualistas, que, por tanto tempo, traçaram a história da humanidade.

Dessa parte do direito civil chegou Lacerda DE Almeida a afirmar que se tratava da mais acentuadamente histórica, mais refratária à transformação e ao progresso, constituinúo mesmo a verdadeira sede das fôrças conservadoras na dinâmica geral do direito.

Aliás, não é difícil explicar essa aparente fidelidade do direito das coisas à doutrina tradicionalista. Direito das coisas è direito de propriedade, que é a base da riqueza social e da felicidade humana, o mais importante e o mais sólido de todos os direitos subjetivos outorgados 
ao indivíduo, o protótipo da prerrogativa absoluta, na fræse de Josserand, e que, mantendo o mesmo paradigma traçado pelo direito romano, conservou, por mais longo tempo, a mesma fisionomia de outrora.

Torna-se inquestionável, porém, que êsse ramo do direito civil, notadamente nos últimos anos, vem sofrendo constantes e sensíveis alterações, determinadas por três fatôres diversos: a preponderância do interêsse público sôbre o particular, a progressão constante do socialismo e a natural fôrça de expansão inerente ao direito das coisas, a atrair novas relações jurídicas para a sua órbita.

Mercê daqueles dois primeiros fatôres, numerosas limitações impuseram-se ao direito de propriedade, que não mais se reveste do caráter absoluto e intangível, de que antigamente se impregnava. Na hora presente, em tồda a parte, sujeita-se êle a várias restriçóes, cada vez mais extensas, reclamadas pelo interêsse social e pelo bem estar da coletividade.

A propriedade, de base individualista foi substituida por outra propriedade, de matizes sociais. Verifica-se assim, como diz Savatier, o crepúsculo da mística do direito de propriedade. Um antigo e acatado professor desta casa, José Augusto CÉSAR, ressaltava que com êsse direito estava a suceder o mesmo que vinha acontecendo paulatinamente com a ilha de Heligoland, da qual as ondas do mar do Norte, todos os anos, levavam um pedaço.

7. Igualmente, alteraram-se as bases do direito das sucessões. Ontem, eram o privilégio da varonia e o direito de primogenitura que dêle se eliminavam urbi et orbe. O mesmo veio a suceder com o direito do ádvena (droit d'aubain). Presentemente, é a ordem de vocação hereditária que se restringe, ou a liberdade testamentária que se amplia, enquanto tende a desaparecer o instituto da deserdação.

8. Por fim, o mesmo acontece ainda com o direito de família. De fato, o casamento, seu instituto funda- 
mental, eixo em tôrno do qual gravita todo o sistema jurídico familiar, se acha em crise, devido à luta que tem de sustentar, na atualidade, com a instituição extra-legal, o concubinato.

Busca-se presentemente, seja claramente ou de modo. disfarçado, recorrendo-se muitas vêzes a sofismas, estabelecer completa igualdade entre a família natural e família legitima. Numerosas decisões tendem a fazer da união livre uma instituição jurídica à margem do casamento e, na hora atual, tende a aumentar cada vez mais o número de casais irregularmente constituídos, de tal maneira que se vai ao ponto de afirmar ser o concubinato a forma normal de união para o futuro.

Por outro lado, o divórcio ganha terreno, esquecidos seus adeptos de que o mesmo degrada o matrimônio, aproximando-o do concubinato, destroi a autoridade paterna e aniquila a piedade filial. $O$ primeiro e surpreendente efeito do divórcio, diz o padre Leonel Franca, é paradoxalmente evitar a prole.

Busca-se mais, em nome de uma falsa piedade, favorecer 0 reconhecimento dos filhos ilegítimos, dando-se assim um grande passo para a normalização do concubinato. Finalmente, surge na tela judiciária o grave problema da inseminação artificial, que, acolhida, destruirá as linhas clássicas do direito de família.

9. Se aplaudimos incondicionalmente aquelas trans.formações processadas no direito das obrigações, no direito das coisas e no direito das sucessões, que mostram ser inexata a afirmativa de que o direito civil é moroso, indigente e improgressivo, não podemos louvar, todavia, as novas idéias que se introduzem no âmbito do direito de familia.

Essas novas idéias tendem a tornar ainda mais instável a instituição da família, que é, sem contestação, o núcleo fundamental, a base mais sólida, em que repousa tôda a organização social. 
É em seu seio que se aprendem os primeiros ensinamentos da religião, as primeiras idéias do dever, do direito, da justiça e da injustiça, o amor da pátria e o respeito às leis. Justamente por isso foi chamada de "santuário dos afetos" (Nuovo Digesto Italiano, voc. Famiglia).

Como diz Cronin, numa era de medo e de inquietação, como a que atravessamos, em que o homem se vê cercado por fôrças hostis, em que se sente perdido na mais negra solidão, é a família sua maior, sua derradeira esperança, da qual dependem sua auto-preservação, a manutenção $d x$ dignidade humana e a decência da vida.

Compreende-se a insurreição dos fatos contra o Código. Justificam-se os profundos golpes que lhe foram desferidos nos demais domínios do direito. Mas não se legitimam os ataques desfechados à família, através da complacência cada vez maior com o divórcio, a união livre e a filiação ilegítima.

Tenho para comigo que os adeptos dessas idéias estão a fazer éco à apóstrofe de GIDE: "familles, je vouls haïs" procuram êles, é certo, sustentar suas convicções, abroquelando-se ora numa idéia de justa aceleração do direito, ora numa tendência de cunho realista.

Acredito, porém, sinceramente, que em direito de família é a tradição a luz que deve guiar nossos passos. Sob a sua inspiração devemos caminhar. Êsse ainda o meio mais seguro de não nos perdermos. Não sou atrasado, nem infenso ao progresso, mas no direito de familia repito o velho aforismo: o que é bom não é novo, o que é novo não é bom.

Acreditó ainda, com LARombière, que devamos evitar o excesso de lançar-nos muito à frente, a pretexto de que não desejamos ficar para trás. O progresso, em tudo, não consiste senão no desenvolvimento regular daquilo que existe, e não na impaciência, na sofreguidão e na ânsia de alterações, cuja primeira e inevitável conseqüência é acarretar a desordem.

Procuremos pois defender as instituições jurídicas, seculares e imemoriais, tais como nos foram legadas pelos 
nossos antepassados. Não nos precipitemos. Saibamos aguardar a lenta formação do direito. Nesse tema, como adverte Clóvis Paula da Rocha, preciso é que as idéias não avancem demais.

Aqui, mais do que em qualquer outro ramo, torna-se necessário que não ocorra o primado do interêsse individual bem como do egoísmo, sôbre o interêsse do grupo familiar. Mais do que um livro de interêsses, o Código há de ser um livro de sentimentos.

A perfeita união dêsse grupo, a integral coesão de todos os seus membros, sob a égide da lei, há de ser, dentro, da tradição da família brasileira, a preocupação máxima de todos nós, professôres e alunos, desta Faculdade e de tôdas as escolas.

10. Mas aqui voltamos à mesma idéia inicial. $O$ direito é um verdadeiro mundo, cujo estudo requer pensamento e reflexão. Entreguêmo-nos a êsse estudo, que outra coisa não é, na frase de Sertillanges, senão uma prece à verdade.

Cada dia que passa aumentam suas dificuldades. Hoje - direito constitui cerrado sistema, que só à custa de muito sacrifício consegue o jurista dominar.

Mas há um segrêdo para o conseguir e vou revelá-lo aos caros estudantes que me ouvem. Houve outrora um rei oriental, que, desejando conhecer a história do homem, recebeu de um sábio 500 volumes.

Atarefado com seus múltiplos problemas, solicitou-lhe que os condensasse. Ao cabo de 20 anos volveu o sábio, e sua história não tinha agora mais que 50 volumes. Mas o rei, demasiado velho então para ler tão massudos tomos, pediu-lhe que resumisse ainda mais a história.

Passaram-se outros 20 anos e o sábio, velho e encanecido, trouxe um único livro, no qual se continha tôda a ciência que o rei procurava. Mas êste jazia em seu leito de morte e não lhe sobrava mais tempo para ier nem mesmo aquêle único volume. $\mathrm{O}$ sábio narrou-lhe então 
a história do homem numa única linha, numa só trase. Era esta: nasceu, sofreu e morreu.

Igualmente, no tocante ao direito, expediram-se códigos e leis, escreveram-se livros e tratados, proferiram-se lições e ensinamentos. Se alguém buscasse, como aquêle sábio da nossa história, numa só frase condensar a ciência jurídica universal, num só periodo abreviar todo o direito, encontraria nos três preceitos do direito romano todo o seu resumo: honeste vivere, neminem laedere e suum cuique tribuere.

Honeste vivere:-a manutenção da dignidade moral do individuo quanto aos seus atos exteriores; neminem laedere, o respeito aos outros homens; suum cuique tribuere, o reconhecimento dos direitos adquiridos pelos nossos semelhantes.

Aquêle que obedece êsses preceitos, conhece a ciência do justo e do injusto. Não se julgue, pois, errôneamente, que nossa civilização haja atingido seu zênite. Ainda que o homem já tenha logrado fracionar o átomo, ainda que êle se apreste para comunicar-se com outros corpos celestes, ainda que êle domine o infinito da astronáutica, desvendando-lhe os mistérios, estaremos ainda, como diz EMERson na fase em que os galos apenas saudam o despontar da alvorada, 